Acta Veterinaria (Beograd), Vol. 63, No. 5-6, 677-685, 2013.

DOI: 10.2298/AVB1306677H

UDK: 615.277.3+616-08:617.711-002/-003:636.7

\title{
CYCLOSPORINE A (CsA) TREATMENT OF CHRONIC AUTOIMMUNE-MEDIATED KERATOCONJUNCTIVITIS SICCA IN DOGS
}

\author{
HADŽI MILIĆ M, ĐORĐEVIĆ JELENA and KRSTIĆ N \\ University of Belgrade, Faculty of Veterinary Medicine
}

(Received $28^{\text {th }}$ February 2013)

\begin{abstract}
The paper is a five year retrospective study of the efficacy of $0.2 \%$ Cyclosporine $A$ eye cream in the treatment of chronic autoimmunemediated KCS in dogs. 114 dogs of 32 breeds, both sexes, and different ages with chronic autoimmune-mediated KCS were treated with $0.2 \%$ Cyclosporine $A$ in the form of eye cream (Optimmune $₫$, Schering Plough Animal Health) applied to the lower lid conjunctiva at a dose of $6 \mathrm{~mm}$ length of the cream strip every 12 hours, during 90 days. Dogs treated with CsA had an improved STT score, specially dogs which had STT values $>5 \mathrm{~mm} / \mathrm{min}$ at the start. Improvement of the clinical picture and healing of superficial corneal lesions were also recorded.
\end{abstract}

Key words: autoimmune-mediated, Cyclosporine A, dogs, keratoconjunctivitis sicca, Schirmer Tear Test

\section{INTRODUCTION}

Keratoconjunctivitis sicca (KCS), known as "dry eye", is a chronic eye disorder often found in small pets, most common in dogs. It is characterised by drying of the eye surface with subsequent inflammation, pain, progressive changes of the cornea and ultimate vision loss. Blepharospasm may be present. The developed blepharospasm is the result of pain and unconfort caused by the lack of PSF. The clinical picture of KCS is often accompanied by inflammatory cells and neovascularization which infiltrate the cornea, thus making it keratinized, opalescent and hypertrophic. The most recognizable clinical sign of KCS is the presence of a mucopurulent-like eye discharge. Because of this usually extensive and thick eye discharge this disorder is often wrongly diagnosed as conjunctivitis of bacterial origin, or even as non specific conjunctivitis, and as a result inadequate therapy was frequently described, resulting with severe consequences (Slatter, 1990, 2003; Gelatt, 1991; Roberts, 1991; Maggs et al., 2008; Bedford et al., 2009; Martin, 2010). 
In all patients eye swabs should be taken in order to determine the bacterial microflora. In order to establish the correct diagnosis the following diagnostic tests should be performed: Schrimer Tear Test (STT), tear brake up time (BUT), Rose Bengal test, biomicroscopic examination with a slit lamp, altogether in combination with the clinical picture (Van-Bijsterveld, 1990; Kaswan et al., 1994; Nelson, 1994; Lang et al., 2000; Maggs et al., 2008).

Therapy can be differenciated into conservative and surgical. Conservative treatment is mainly based on substitutional therapy (artefitial tears), while surgical treatment is based on the correction of opthalmic disorders by reconstructive surgery. Before the introduction of cyclosporine A surgical treatment was often applied, but with poor results (Slatter, 1990, 2003; Sansom et al., 1994; Kaswan et al., 1994; Bedford et al., 2009).

Topical application of cyclosporine A (CsA - Optimmune $\left.{ }^{\circledR}\right)$ is one of the latest established approaches in the treatment of KCS. Cyclosporine has been used in human medicine for its immunosupressive features required after organ transplantation (Kaswan, 1990; Brayan, 1992; Kaswan et al., 1994). Unlike other immunosupressants CsA specifically acts on lymophcytes without interfering with neutrophils. Its activity is based on the action on T- helper cells which are inhibited and thus the synthesis of proinflammatory cytokines is halted (Kaswan et al., 1994; Kaswan, 1994). Cyclosporine acts within T- cells, after antigen binding leads to the blockade of gene sequences, hence blocking lymphokine synthesis. Such a reaction results in the inhibition of $T$-helper cells and subsequent immunotolerance (Bistner, 1994; Kaswan et al., 1985, 1994, Kaswan, 1990, 1994). The efficiency of the treatment largely depends on the stage of deterioration of the lacrimal glands (Bryan, 1992 ; de Rojas et al., 1993; Sansom et al., 1994; Kaswan, 1994; Bistner, 1994; Christmas, 1994).

The purpose of this study was to demonstrate the efficacy of topical $0.2 \%$ Cyclosporine $\mathrm{A}(\mathrm{CsA})$ eye oinment in the treatment of chronic autoimmunemediated keratoconjunctivitis sicca (KCS) in dogs. Medical records of dogs diagnosed with autoimmune-mediated KCS at the Clinic of Surgery, Orthopaedic and Ophthalmology, Faculty of Veterinary Medicine, Belgrade in the period between 11.09.2007. and 15.06.2012 were reviwed.

\section{MATERIAL AND METHODS}

The study was performed on 114 dogs (32 breeds) which were regular patients at the Clinic of Surgery, Orthopaedic and Opthalmology, Faculty of Veterinary Medicine, Belgrade in the period from 11.09.2007. until 15.06.2012. The age of the patients ranged from 1 to 14 years with a mean age of 5.5 years. $A$ complete ophthalmic examination consisted of: Schirmer tear test (STT), corneal dying with Rose-Bengal and fluorescein, tear break-up time, biomicroscopy with a slit lamp. Diagnosis of KCS was based upon the clinical signs in one or both eyes and the above listed tests (mainly STT and confirmed with biomicroscopy) 
(Kaswan et al., 1994; Nelson, 1994; Nelson, 1994; Lang et al., 2000; Maggs et al., 2008).

All patients were treated with $0.2 \%$ cyclosporine-A eye cream (Optimmune ${ }^{\circledR}$, Schering-Plough Animal Health) (Kaswan, 1990, 1994; Bryan, 1992; Christmas, 1994; Sansom et al., 1994). The dose was defined by the length of the cream strip ( $1 \times 6 \mathrm{~mm}$ ) applied to the lower lid conjuctiva. The CsA eye ointment was applied twice a day (every 12h). The lacrimomimetic effect decreased 12 hours after application, hence the raccomandation to repeat the application at every 12 hours. Recheck examinations were scheduled at 10, 20, 30, 40 and 90 days after initiation of Cyclosporine A (CsA) therapy.

\section{RESULTS}

\section{Signalment}

Over a period of 5 years, 114 dogs (218 eyes) with KCS met the criteria for inclusion in the study. Sixty-five males and forty-nine females. The age at time of diagnosis ranged from 1 to 14 years with a median of 5.5 years. The represented breeds were: Pekingese $(n=15)$, Mixed breed dogs $(n=9)$, Shih Tzu $(n=8)$, West Highland White terrier $(n=7)$, Pug $(n=7)$, Chihuahua $(n=6)$, Yorkshire terrier $(n=6)$, Maltese $(n=5)$, English bulldog $(n=5)$, Boston terrier $(n=5)$, Schnauzer $(n=4)$, Miniature schnauzer $(n=4)$, Bull terrier $(n=4)$, Chow chow $(n=3)$, Dachshund $(n=3)$, Boxer, Bloodhound, Akita, Serbian Defence Dog, Samoyed and Tibetan spaniel (two of each) and one of Labrador retriever, Kerry blue terrier, German shepherd, Cocker spaniel (American and English), Lhassa apso, Dalmatian, Dobermann, Airedale terrier, German Jagdterrier and Miniature Pinscher (Kaswan et al., 1985; Slatter, 1990; Bistner, 1994; Maggs et al., 2008; Bedford et al., 2009; Martin, 2010).

KCS on both eyes was diagnosed in 104 dogs $(91.23 \%)$. The OD was affected in 109 dogs; the OS in 109 dogs. Because of different degree of lack of tears, animal's eyes (218) were allotted into three groups:

1. with STT value $<5 \mathrm{~mm} / \mathrm{min}$;;

2. STT from 5 to $10 \mathrm{~mm} / \mathrm{min}$;

3. STT >10 (<15) $\mathrm{mm} / \mathrm{min}$.

In the first group there were 57 eyes, in the second group 118, and in the third 43 eyes. Ten were with normal lachrymation. Eight dogs (7.02\%) were with STT values $<5 \mathrm{~mm} / \mathrm{min}$. on both eyes; mostly males (7 of $8 ; 87.5 \%$ ); age ranged from 1 to 13 years with a mean age of 6.4 years. Twenty-nine (25.44\%) had STT values from 5 to $10 \mathrm{~mm} / \mathrm{min}$. on both eyes; 16 males and 13 females $(55.2 \% \mathrm{~m}$.; $44.8 \%$ f.); age ranged from 1 to 14 years (average age of 5.6 years). Two dogs $(1.75 \%)$, both females about 8 years old, had lacrimation over $10 \mathrm{~mm} / \mathrm{min}$. on both eyes. 


\section{Clinical findings}

On three eyes (1.38\%), in which STT was $>10 \mathrm{~mm} / \mathrm{min}$., there were no clinical signs. Mild to more pronounced hyperaemia was present in all other cases. With mild clinical signs there were 69 eyes (31.65\%); 30 eyes $(43.48 \%)$ with STT value $<5 \mathrm{~mm} / \mathrm{min}$. and $39(56.52 \%)$ with STT from 5 to $10 \mathrm{~mm} / \mathrm{min}$. In these cases rimus lacrimalis was thinned, mild to more pronounced blepharospasm was present, due to pain and discomfort, and secretion was slightly denser. Examination on biomicroscope showed mucin fibers (Roberts, 1991; Gelatt, 1991; Lang et al., 2000; Lang et al., 2000; Maggs et al., 2008).

With moderate clinical picture of KCS there were 88 eyes $(40.37 \%) ; 4$ eyes (4.54\%) with STT $<5 \mathrm{~mm} / \mathrm{min}, 83$ eyes $(94.32 \%)$ STT from 5 to $10 \mathrm{~mm} / \mathrm{min}$., and $1(1.14 \%)$ with STT $>10 \mathrm{~mm} / \mathrm{min}$. Severe to mild keratitis with considerable ocular discharge was present in all cases. Rimus lacrimalis was extremely thin or absent. Eyes were not as shiny and wet, and on biomicroscopic examination mucine fibers were observed (Roberts, 1991; Gelatt, 1991; Lang et al., 2000; Barnett, 2006; Maggs et al., 2008).

Severe symptoms of KCS were diagnosed in 58 eyes (26.6\%); 53 (91.38\%) with STT $<5 \mathrm{~mm} / \mathrm{min}$. and $5(8.62 \%)$ with STT from 5 to $10 \mathrm{~mm} / \mathrm{min}$. In these cases were noted dry nostrils, blepharitis of different degree and copious, dense, tacky, purulent-like discharge adherent to the cornea and often present in the conjunctival fornices. Severe keratitis and severe degenerative changes on the cornea with the emergence of neovascularization and pigmentation were also present. Fifteen eyes in this group (15 of $53 ; 28.3 \%$ ) were with STT value 0 ; in 3 of these eyes corneal surface stained positive with fluorescein (Hemady et al., 1990; Roberts, 1991; Gelatt, 1991; Hovding, 1992; Lang et al., 2000; Barnett, 2006; Maggs et al., 2008).

\section{Treatment and outcome}

Infection was present in 27 dogs. These patients were treated at first with antibiotics according to the results of the antibiogram, and after sanation of the infection treated with CsA. In three cases with corneal ulcers (Hemady et al., 1990; Hovding, 1992) the same were repaired using adequate conservative or surgical treatment and after that started with the treatment for KCS. As supportive therapy in cases with a severe clinical picture artificial tears were applied 4 to 5 times a day but not the day before and on the day of measurement.

All patients were treated with $0.2 \%$ cyclosporine-A eye cream (Optimmune ${ }^{\circledR}$, Schering-Plough Animal Health). The dose was defined by the length of the cream strip ( $1 \times 6 \mathrm{~mm}$ ) applied to the lower lid conjunctiva. The CsA eye ointment was applied twice a day (every $12 \mathrm{~h}$ ).

The first control examination after 10 days showed an improvement of tear production in 25/57 (43.86\%) cases with STT<5 mm/min; 104/118 (88.14\%) with $\mathrm{STT}=5-10 \mathrm{~mm} / \mathrm{min}$. and $41 / 43(95.35 \%)$ with STT $>10<15 \mathrm{~mm} / \mathrm{min}$ (Figure 1). 


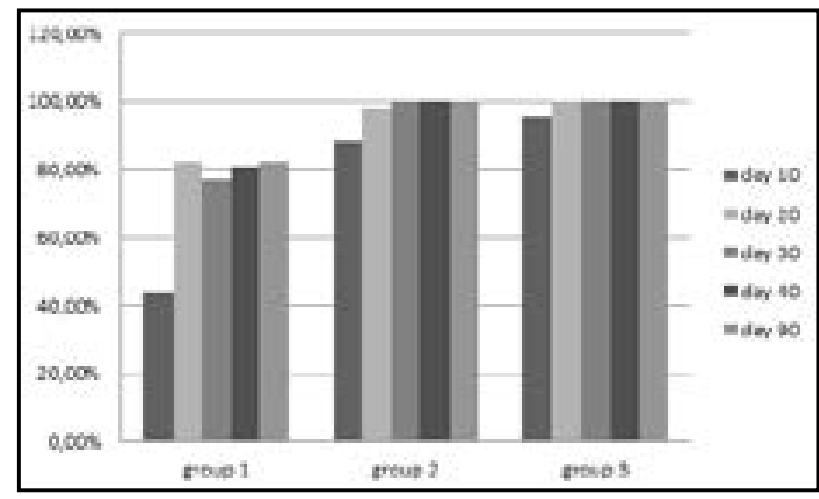

Figure 1. Improvement in STT values compared to the start values in all three groups

After 20 days STT value improvement was present in $47 / 57$ eyes $(82.46 \%)$ in the first group, $116 / 118(98.3 \%)$ eyes in the second and $43 / 43(100 \%)$ eyes in the third group, compared to the first measurement (Figure 1). In the first group STT value was increased in $44 / 57(77.19 \%)$ eyes, stagnated in $7 / 57(12.28 \%)$ and lower in $6 / 57(10.53 \%)$ eyes, compared to the previous measurement. In
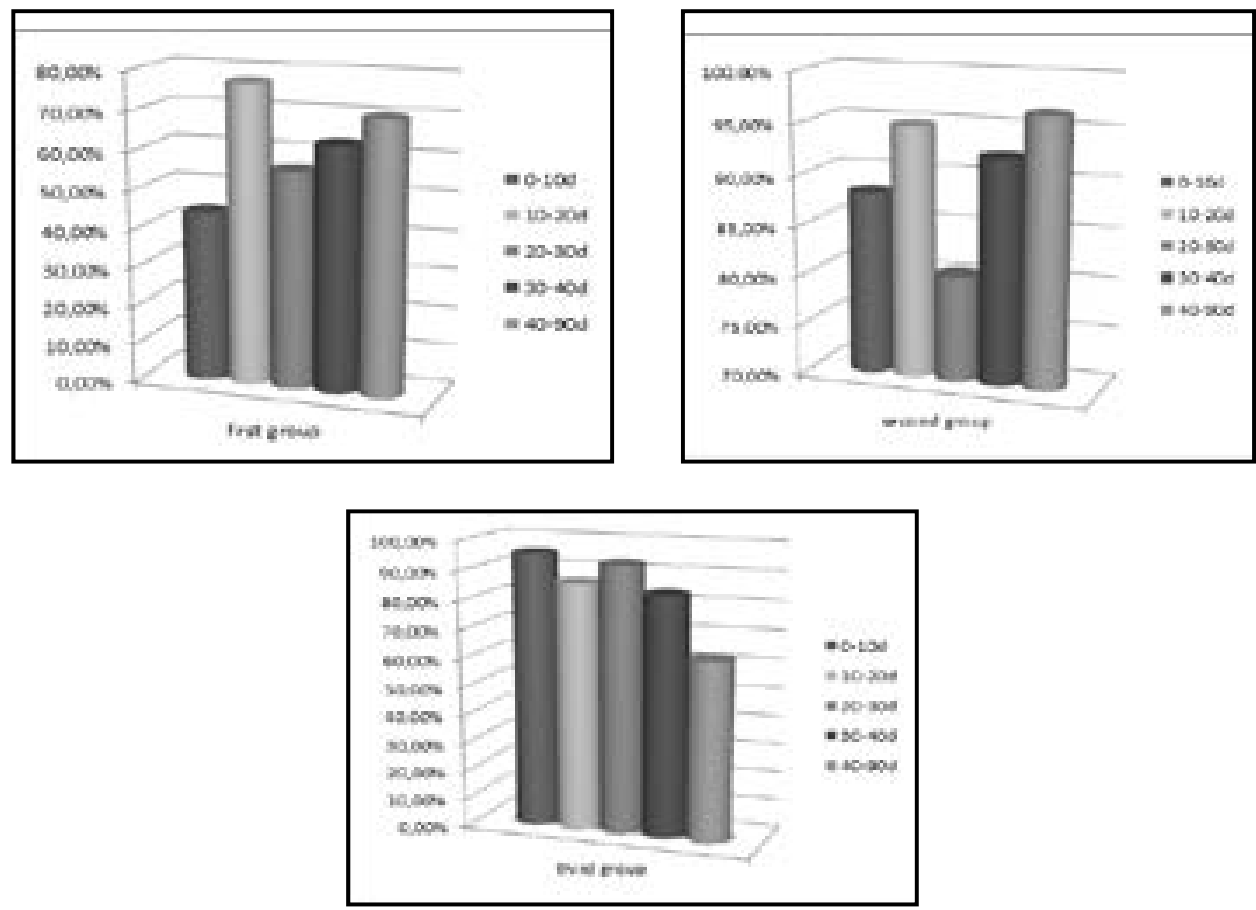

Figure 2. Percentage of increase of STT value compared to the previous measurements 
the second group was increased in $94.91 \%$ (112/118 eyes), unchanged in $4.24 \%$ (5/118 eyes) and lower in $0.85 \%$ (1/118 eye). In the third group STT value was increased in $86.05 \%$ (37/43 eyes), unchanged in $9.3 \%$ (4/43 eyes) and lower in $4.65 \%$ (2/43 eyes), compared to the previous measurement (Figure 2).

Ten days after (day 30) the first group showed an improvement of $77.19 \%$ $(44 / 57)$, while it reached $100 \%$ in the second and third group (Figure 1). In the first group STT value was increased in $56.14 \%$ (32/57), unchanged in $22.81 \%(13 / 57)$ and lower in $21.05 \%$ (12/57). In eyes which had at the start STT values from 5 to $10 \mathrm{~mm} / \mathrm{min}$, increase in tear secretion was measured in $80.51 \%$ (95/118), was not changed in $15.25 \%(18 / 118)$ and decreased in $4.24 \%(5 / 118)$. In the third group STT value was increased in $93.02 \%$ (40/43) and unchanged in $6.98 \%(3 / 43)$ (Figure 2). There was no reduction in tear secretion.

After 40 days of treatment, the STT value increased in $46 / 57(80.70 \%)$ eyes with STT $<5 \mathrm{~mm} / \mathrm{min}$, while in other two groups improvement was noted in all cases $(100 \%)$ (Figure 1). Compared to the previous measurement, tear secretion was greater in $63.16 \%(36 / 57)$, unchanged in $31.58 \%$ (18/57) and decreased in $5.26 \%$ (3/57) from the first group. In eyes which had a value of STT from 5 to $10 \mathrm{~mm} / \mathrm{min}$ at the start, increase in tear secretion was measured in $92.37 \%$ (109/118), there was no change in $6.78 \%(8 / 118)$ and decreased production of tears was present in $0.85 \%(1 / 118)$, compared to the $30^{\text {th }}$ day. In 36 cases $(83.72 \%)$ from the third group lacrymation was improved, in 6 (13.95\%) remained at the same level, and in $1(2.33 \%)$ was lower than in the previous measurement (Figure 2$)$.

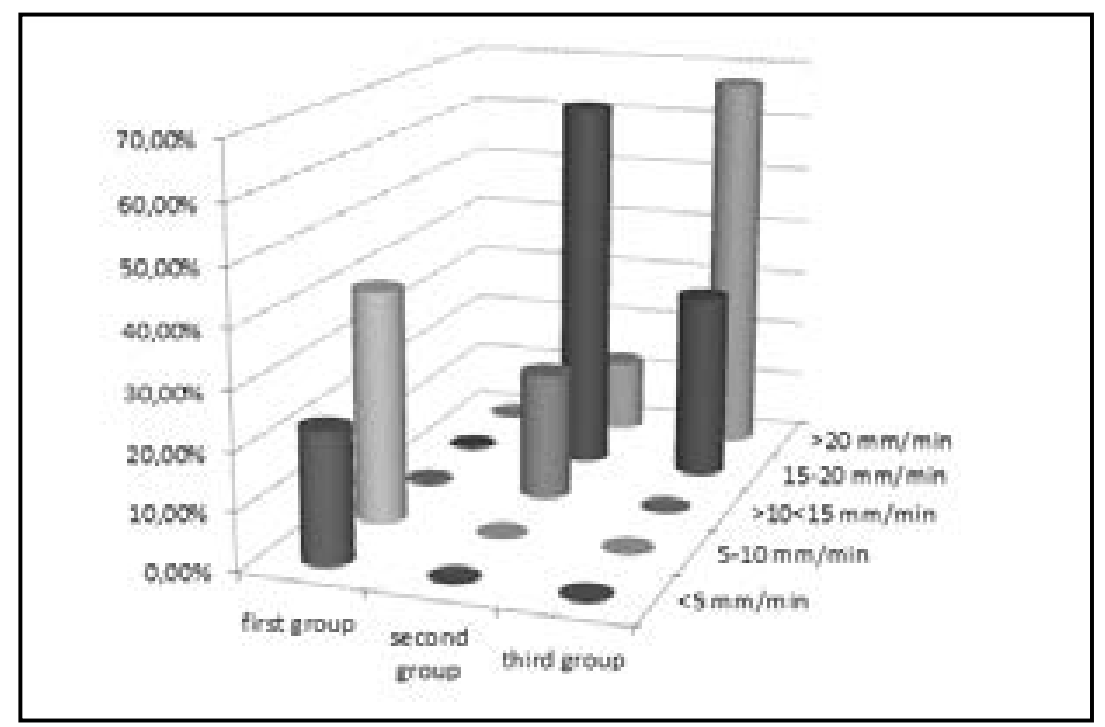

Figure 3. Comparison of the percentage of cases with different degree of tear secretion measured at day 90 of CsA treatment 
After 90 days of treatment (Figure 1,2) lachrymation was greater in 47/57 $(82.46 \%$ ) eyes from the group 1 (13 of these were still under $5 \mathrm{~mm} / \mathrm{min} ; 23$ were from 5 to $10 \mathrm{~mm} / \mathrm{min}$.; 11 were more than $10 \mathrm{~mm} / \mathrm{min}$ ) (Figure 3). Increased lacrymation was present in $40(70.18 \%)$ eyes, without change were $16(28.07 \%)$ and an increase was observed in one eye (1.75\%). In the second group all values were greater than at the start; there were 114 eyes (96.61\%) with increased, 2 (1.69\%) unchanged and $2(1.69 \%)$ with decreased STT value, compared with day 40.26 eyes were with STT $=10-15 \mathrm{~mm} / \mathrm{min}, 77$ with STT $=15-20 \mathrm{~mm} / \mathrm{min}$ and 15 with STT $>20 \mathrm{~mm} / \mathrm{min}$ (Figure 3). In the third group STT value was increased in all cases; compared to the previous measurement, increase was noted in 27 $(62.79 \%)$ eyes, without change was $16(37.21 \%)$. Fourteen eyes were with STT from 15 to $20 \mathrm{~mm} / \mathrm{min} ; 29$ with STT $>20 \mathrm{~mm} / \mathrm{min}$ (Figure 3).

No response to treatment was noted in 9 dogs (10 eyes; 7 with STT=0; 2 with $\mathrm{STT}=1 ; 1$ with $\mathrm{STT}=2$ ).

\section{DISCUSSION}

In this study, KCS occured often in male dogs (57.02\%). The age of patients varied but animals between 3 and 8 years of age were most common. The patients presented with bilateral KCS in 104 cases $(91.23 \%)$ and occurred unilateral in ten dogs $(8.77 \%)$. All patients were treated with $0.2 \%$ Cyclosporine-A eye cream twice a day during the 90 days.

The Cyclosporine treatment was stopped in 16 dogs due to the occurrence of infection. After infection was cured CsA treatment was continued.

Results show that the increase in lacrimal secretion in the left eye was more evident during the first 10 days of treatment when compared to the right eye. However, in the following 10 days the right eye lacrimal secretion showed an improvement, while the left eye mantained a steady rate of increase. After 20 days the right eye tear secretion was stable with an insignificant drop in STT values.

In our study improvement in tear secretion after 10 days of therapy was least expressed in cases which had STT value $<5 \mathrm{~mm} / \mathrm{min}$. The greatest response to CsA treatment in this group was after 20 days of therapy, after which it decreased significantly (on $30^{\text {th }}$ day) and during the following period showed a modest increase by the $90^{\text {th }}$ day. However, none of these eyes exceeded the value of $10 \mathrm{~mm} / \mathrm{min}$. Ten of 57 eyes showed no response to treatment, among them one dog (1 year old Yorkshire terrier) was without lachrymation on both eyes (STT=0) at start and during the entire study, on what basis we can express doubt on the existence of congenital alacrima (Westermeyer et al., 2009).

In the second group in most cases the eyes showed big improvement on the $20^{\text {th }}$ day; on $30^{\text {th }}$ day improvement was in stagnation, after which they showed significant progress with final STT values in most cases from 15 to $20 \mathrm{~mm} / \mathrm{min}$.

In third group the improvement was most balanced during testing. At start it was in significant progress with minor variations during the next three rechecks. 
The STT values in the last two measurements were fairly constant; the highest number of cases was with STT over $20 \mathrm{~mm} / \mathrm{min}$.

The results showed that in patients who had STT value $<5 \mathrm{~mm} / \mathrm{min}$ therapy did not lead to any significant improvement and was ineffective. Unlike the first group, in the second and the third therapy with CsA was very effective and resulted in a significant improvement in tear secretion, which shows that the efficiency of the treatment largely depends on the state of the lacrimal glands parenchyma (Kaswan et al., 1985, 1994; Bryan, 1992; de Rojas et al., 1993; Sansom et al., 1994; Kaswan, 1994; Bistner, 1994; Christmas, 1994).

At the same time, the existing symptoms of KCS, such as corneal disorders and neovascularization were alleviated, which may be associated with the effect of CsA on lacrimal glands and increase of tear secretion, but also with its direct effect on corneal and conjunctival tissue.

\section{REFERENCES}

1. Barnett K, 2006, Diagnostic Atlas of Veterinary Ophthalmology, 2nd. ed., Mosby Elsevier, Edinburgh, New York.

2. Bedford PGC, 2009, Small Animal Ophthalmology, 4th. ed., Elsevier Limited, 283-91.

3. Bistner S, 1994, Alergic and immunologic - mediated disease of the eye and adnexae, Vet Clin North Am Small Anim Pract, 24, 4, 711-34.

4. Bryan GM, 1992, Perspective, patience, and cyclosporine (letter), JAVMA, 200, 2, 136.

5. Christmas $R, 1994$, Canadian Open Clinical Field Study of Cyclosporine Ophthalmic Ointment in Dogs with Keratoconjunctivitis Sicca. Papers from a meeting held in conjunction with the meeting of the ESVO-ECVO, Dresden, Germany.

6. de Rojas $M V, 1993$, Impression cytology in patients with keratoconjunctivitis sicca, Cytopathology, 4, 6, 347-55.

7. Gelatt KN, 1991, Veterinary Ophthalmology, sec.ed. Lea \& Febiger, Philadelphia.

8. Hemady R, 1990, Keratoconjunctivitis sicca and corneal ulcers, Cornea, 9. 2, 170-3.

9. Hovding G, 1992, The central corneal thickness in keratoconjunctivitis sicca, Acta Ophthalmol Copenh, 70, 1, 108-10.

10. Kaswan RL, 1994, Diagnosis and Medical Management of Keratoconjunctivitis Sicca. Papers from a meeting held in conjunction with the meeting of the ESVO-ECVO, Dresden, Germany.

11. Kaswan RL., 1985, Keratoconjunctivitis Sicca: immunological evaluation of 62 canine cases, Am $J$ Vet Res, 46, 376-83.

12. Kaswan RL, Salisbury MA, 1990, A New Perspective on Canine Keratoconjunctivitis sicca: Treatment with Ophthalmic Cyclosporine, Vet Clin North Am Small Anim Pract, 20, 3, 583-613.

13. Kaswan RL, 1994, Ophthalmic Cyclosporine: Imunology and Investigational Indicationas. Papers from a meeting held in conjunction with the meeting of the ESVO-ECVO, Dresden, Germany.

14. Lang GK, 2000, Ophthalmology, A Short Textbook, Stuttgart, Germany, 52- 7.

15. Maggs D, Miller P, Ofri K, 2008, Slatter's Fundamentals of Veterinary Ophthalmology, WB Saunders, Philadelphia.

16. Martin CL, 2010, Ophthalmic Disease in Veterinary Medicine, Manson Publishing LTD, London, 222-30.

17. Nelson JD, 1994, Diagnosis of keratoconjunctivitis sicca, Int Ophthalmol Clin, 34, 1, 37-56.

18. Roberts DK, 1991, Keratoconjunctivitis sicca. J Am Opt Assoc, 62, 3, 187-99.

19. Sansom J., 1994, Long-Term Study on the Efficacy of Cyclosporine Ophthalmic Ointment in 
the Treatment of Chronic Keratoconjunctivitis Sicca in the Dog. Papers from a meeting held in conjunction with the meeting of the ESVO-ECVO, Dresden, Germany.

20. Slatter $D$, 1990, Fundamentals of Veterinary Ophthalmology, 2nd. ed. W.B. Saunders, Philadelphia.

21. Slatter D, 2003, Textbook of Small Animal Surgery. 3rd. ed. vol.2. W.B. Saunders, Philadelphia.

22. Van-Bijsterveld OP, 1990, Diagnosis and differential diagnosis of keratoconjunctivitis sicca associated with tear gland degeneration, Clin Exp Rheumatol, 8 Suppl, 5, 3-6.

23. Westermeyer HD, Ward DA, Abrams $K$, 2009, Breed predisposition to congenital alacrima in dogs, Vet Ophthalmol int J Clin Invest Ophthalmol, Wiley-Blackwell, 12, 1, 1-5.

\title{
CIKLOSPORIN A U TERAPIJI HRONIČNOG AUTOIMUNOG KERATOCONJUNCTIVITIS SICCA KOD PASA
}

\author{
HADŽI MILIĆ M, ĐORĐEVIĆ J I KRSTIĆ N
}

\section{SADRŽAJ}

U ovom radu je izneta petogodišnja retrospektivna studija o efikasnosti ciklosporin A kreme za oči u terapiji hroničnog autoimunog keratoconjunctivitis sicca kod pasa. Ukupno 114 pasa, 32 rase, oba pola i različite starosti sa hroničnim autoimunim KCS tretirano je ciklosporinom A u vidu kreme za oči (Optimmune ${ }^{\circledR}$, Schering-Plough Ainimal Health), aplikovanjem na konjunktivu donjeg kapka u dozi od $6 \mathrm{~mm}$ dužine kreme na svakih 12 sati tokom 90 dana. Kod pasa tretiranih sa CsA došlo je do povećanja vrednosti Širmerovog suznog testa, naročito kod pasa koji su na početku imali STT vrednost $>5 \mathrm{~mm} / \mathrm{min}$. Takođe je došlo i do poboljšanja kliničke slike i izlečenja površinskih kornealnih lezija. 